\title{
DỨBin
}

Technological University Dublin

ARROW@TU Dublin

\section{A Fiber-Optic Voltage Sensor Based on Macrobending Structure}

\author{
Pengfei Wang \\ Technological University Dublin, pengfei.wang@tudublin.ie \\ Yuliya Semenova \\ Technological University Dublin, yuliya.semenova@tudublin.ie \\ Qiang Wu \\ Technological University Dublin, qiang.wu@tudublin.ie
}

See next page for additional authors

Follow this and additional works at: https://arrow.tudublin.ie/engscheceart

Part of the Electromagnetics and Photonics Commons

\section{Recommended Citation}

Wang, P., Semenova, Y., Wu, Q., Farrell, G.:A Fiber-Optic Voltage Sensor Based on Macrobending Structure. Optics and Laser Technology, Vol. 43, 5, 2011, pp.922-924. doi:10.1016/j.optlastec.2011.01.003

This Article is brought to you for free and open access by the School of Electrical and Electronic Engineering at ARROW@TU Dublin. It has been accepted for inclusion in Articles by an authorized administrator of ARROW@TU Dublin. For more information, please contact arrow.admin@tudublin.ie, aisling.coyne@tudublin.ie, gerard.connolly@tudublin.ie.

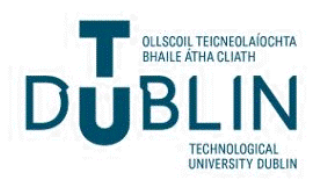


Authors

Pengfei Wang, Yuliya Semenova, Qiang Wu, and Gerald Farrell

This article is available at ARROW@TU Dublin: https://arrow.tudublin.ie/engscheceart/122 


\section{AUTHOR QUERY FORM}

\begin{tabular}{|l|l|l|}
\hline & & Please e-mail or fax your responses and any corrections to: \\
ELSEVIER & Article Number: 2156 & E-mail: corrections.esch@elsevier.macipd.com \\
\hline
\end{tabular}

Dear Author,

Please check your proof carefully and mark all corrections at the appropriate place in the proof (e.g., by using on-screen annotation in the PDF file) or compile them in a separate list.

For correction or revision of any artwork, please consult http://www.elsevier.com/artworkinstructions.

Any queries or remarks that have arisen during the processing of your manuscript are listed below and highlighted by flags in the proof. Click on the $\underline{Q}$ link to go to the location in the proof.

\begin{tabular}{|c|c|}
\hline $\begin{array}{l}\text { Location in } \\
\text { article }\end{array}$ & $\begin{array}{l}\text { Query / Remark: click on the } Q \text { link to go } \\
\text { Please insert your reply or correction at the corresponding line in the proof }\end{array}$ \\
\hline$\underline{\text { Q1 }}$ & $\begin{array}{l}\text { Please check whether the designated corresponding author is correct, and also check the e-mail addresses } \\
\text { for the corresponding, and amend if necessary. }\end{array}$ \\
\hline$\underline{\mathrm{Q} 2}$ & The number of keywords provided exceeds the maximum allowed by this journal. Please delete 1 keyword. \\
\hline
\end{tabular}

Thank you for your assistance. 


\title{
A fiber-optic voltage sensor based on macrobending structure
}

\author{
Pengfei Wang*, Yuliya Semenova, Qiang Wu, Gerald Farrell \\ Photonics Research Center, School of Electronic and Communications Engineering, Dublin Institute of Technology, Kevin Street, Dublin 8, Ireland
}

\section{A R T I C L E I N F O}

\section{Article history:}

Received 7 September 2010

Received in revised form

10 December 2010

Accepted 4 January 2011

Fiber-optic sensor

Voltage sensor

Macrobending loss

Whispering Gallery Mode

\begin{abstract}
A B S T R A C T
We propose and demonstrate an optical voltage sensing scheme based on a macrobending optical fiber in a ratiometric power measurement system. This novel approach to sensing has not been utilized before and has the advantage that the sensor involves simple fabrication compared to existing fiberoptic voltage sensors. To prove the feasibility of such a fiber-optic sensor, a sensor for a voltage range from $0 \sim 100 \mathrm{~V}$ is demonstrated, with a resolution of $0.5 \mathrm{~V}$. The sensor is robust, linear, and shows a competitive measurement resolution. The sensor can be easily scaled to suit other voltage levels and be effectively combined with optical current sensors.
\end{abstract}

(c) 2011 Published by Elsevier Ltd.

\section{Introduction}

Fiber-optic voltage sensors are attractive for high voltage sensing applications as they can provide high dielectric isolation between the high voltage measurement point and the measurement electronics. Such sensors also offer many other advantages compared with conventional voltage sensors such as immunity to electromagnetic interference, light weight, small size, fast response, and a potential for remote operation [1]. Piezoelectric (PZT) devices are often implemented as transducers in fiber-optic voltage sensors. The voltage induces a strain in the PZT as well as in the optical fiber attached to it. The attached optical fiber could be of any type such as a singlemode fiber [2], a hollow fiber [3], or a fiber Bragg grating (FBG) [4]. Depending on the type of the fiber sensor employed the measurement of voltage can be carried out either using the interference between the reflected and incident signal measurement $[2,3]$ or by measuring the reflected signal shifts [4] However these existing schemes require complex and expensive measurement systems to extract either the phase information or the wavelength information in order to measure the voltage. We have previously presented a singlemodemultimode-singlemode (SMS) structure based fiber-optic voltage sensor that utilized a ratiometric power measurement system [5]. In this paper a strong voltage dependence for the transmission loss of the SMS fiber structure can be achieved at a single wavelength facilitating the use of an inexpensive interrogation system. However, the accurate fabrication of an SMS sensing structure still needs a relatively complex fabrication process.

\footnotetext{
* Corresponding author.
}

E-mail addresses: pw3y09@orc.soton.ac.uk, pengfei.wang@dit.ie (P. Wang).
Recently a macrobending fiber structure has been demonstrated for various applications such as: edge filter for the fast wavelength measurement [6], temperature sensor [7], refractive index sensor [8], textile based respiratory rate sensor [9], flowmeter [10], and biosensor [11], In this paper we present for the first time a simple method to measure voltage using a macrobending fiber attached to a PZT stack utilized in a ratiometric power measurement scheme. A DC voltage sensor is demonstrated for a range of voltages from 0 to $100 \mathrm{~V}$, which is suitable for isolated voltage monitoring, for example, in solar power systems or in automotive and aircraft electrical systems. The proposed sensor has the potential to be applied in high voltage sensing applications.

\section{Fiber sensing background and operating principle}

In our previous work [6], a bare 1060XP fiber coated with an absorbing layer has been proposed as an edge filter for wavelength measurement applications. Both theoretical and experimental results have shown that the bend loss monotonically decreases as the bend diameter increases at certain specific wavelengths. Such a characteristic offers a possibility to develop a macrobending-based displacement sensor. The operating principle of such a sensor is based on the fact that a change in the bend diameter of the fiber section causes a change in the bending loss. By measuring the changes in macrobending loss, the variation in bend diameter can be determined and with a suitable calibration the displacement can be measured.

It should be noted that using the bare 1060XP fiber coated with an absorbing layer as the basis for a displacement sensor would result in a low resolution for the proposed sensor. From 
Ref. [12], which also utilizes a 1060XP fiber, one can see that the measured discrimination range (bend loss difference between the bend radius of 8.5 and $14 \mathrm{~mm}$ ) is $15.5 \mathrm{~dB}$ at an operating wavelength of $1500 \mathrm{~nm}$, which yields an estimated resolution for displacement measurement of $0.0014 \mathrm{~dB} / \mu \mathrm{m}$. Given that optical power measurement normally cannot achieve a resolution better than $0.02 \mathrm{~dB}$, the result is that micron order displacement sensing cannot be achieved using this fiber configuration. Furthermore, the limitations of the absorbing layer applied to the fiber surface, evident from the quasi-periodic nature of the measured results, can further degrade the accuracy of displacement measurement.

One possible solution to increase the sensitivity of the proposed macrobending fiber sensor is to utilize the inherent Whispering Gallery Mode (WGM) effect in a fiber bend. Refs. $[13,14]$ have investigated this approach using a bare bending SMF28 fiber, where strong WGMs significantly affect the light propagation through the bending fiber. The measured bend loss results show a large discrimination range $(\sim 7.3 \mathrm{~dB})$ between the bend radii of 6 and $5.5 \mathrm{~mm}$, at a wavelength of $1600 \mathrm{~nm}$ [13]. Such a performance indicates that WGMs could be potentially useful to enhance the sensitivity of a displacement sensor based on a macrobending fiber loop. However because of the low value of bend loss in SMF28, a displacement sensor using SMF28 would require many fiber turns to achieve a reasonable resolution, which in practice would create significant mechanical difficulties for the sensor.

The alternative approach is to use a high bend loss fiber, allowing the sensor to be fabricated with only a half-loop of fiber. In this paper, the proposed fiber displacement sensor consists of a half-loop structure of coating stripped bare high bend loss fiber. The fiber employed in the experiment was a 1060XP singlemode fiber that has a high bend loss over the wavelength range of $1500-1600 \mathrm{~nm}$. Experimentally to fix the diameter of the fiber half-loop, each end of the half-loop is glued to a $20 \mathrm{~mm}$ travel single-axis translation stage, which can achieve a $10 \mu \mathrm{m}$ step resolution. In this way the diameter of the bend fiber can be controlled using the translation stages.

We measured the bend loss of a bare 1060XP fiber with a cladding diameter of $125 \mu \mathrm{m}$ using a tunable laser and an optical spectrum analyzer, for the range of bend diameters from 15 to $18 \mathrm{~mm}$ (the bend length is half turn) in the wavelength range from 1500 to $1600 \mathrm{~nm}$. The bending loss responses in the wavelength range $1500-1600 \mathrm{~nm}$ for different positions of the translation stage are presented in Fig. 1 for bend diameters of circa $17 \mathrm{~mm}$.

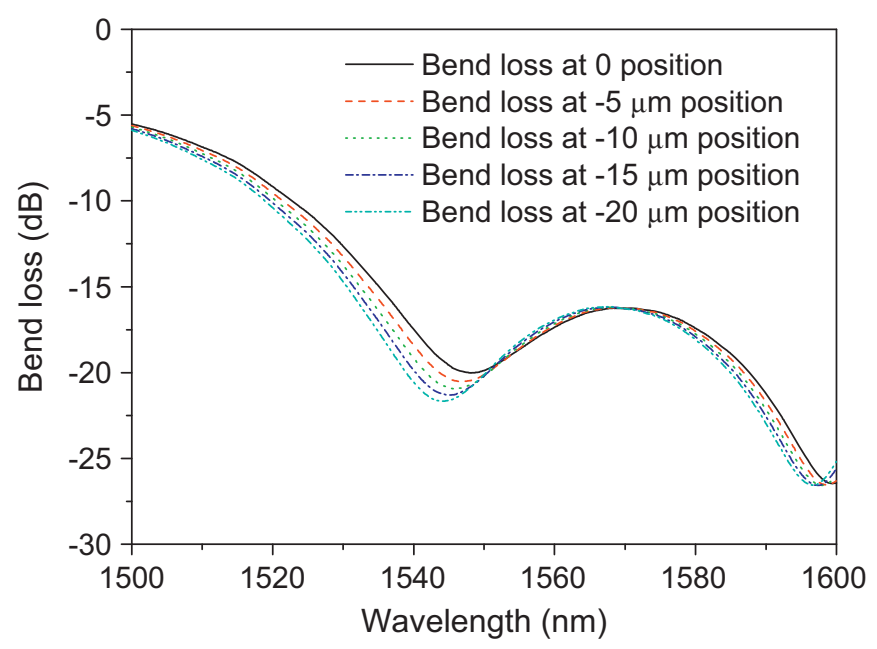

Fig. 1. Bend loss response of a bare bend fiber with a half-loop.

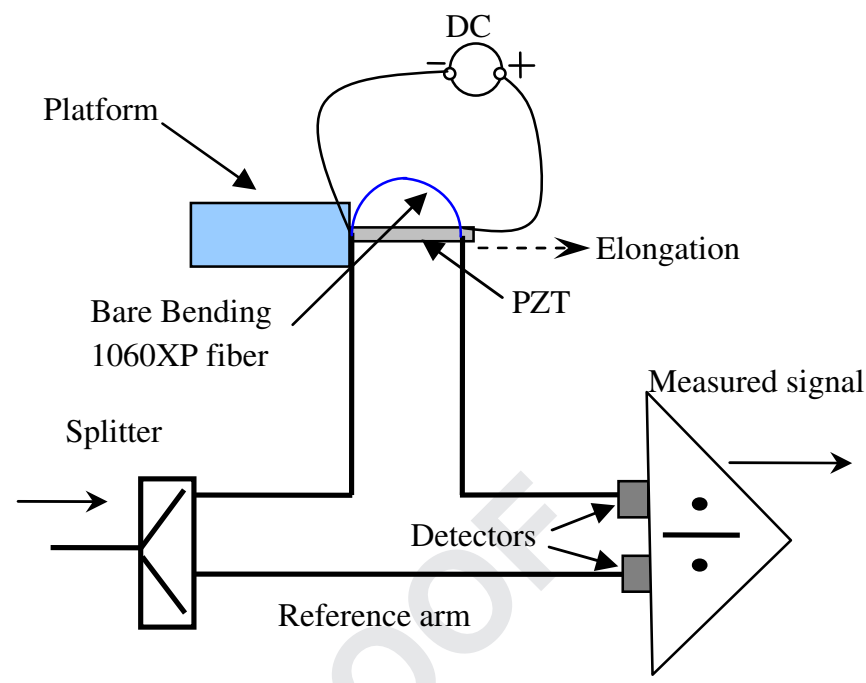

67

69

71

77

79

81

83

85

Fig. 2. Schematic configuration of the proposed bent fiber voltage sensor system.

It is evident from Fig. 1 that for a given bend diameter there is a complex relationship between the transmitted wavelength and bend loss, which arises because of WGMs. At specific wavelengths the presence of WGMs means that the bending loss is a very strong function of the bend diameter. For example, for a wavelength of $1540 \mathrm{~nm}$, one can see that the difference in bend loss between 16.98 and $17 \mathrm{~mm}$ is circa $3.07 \mathrm{~dB}$, which could provide a useful displacement resolution. Note that it is found that beyond the $18 \mathrm{~mm}$ bend diameter the intensity of WGMs is too low to provide a useful sensitivity enhancement, while for bend diameters below $15 \mathrm{~mm}$, the risk of fiber breakage by excessive stress is too high.

The voltage sensor can be built by attaching the half-loop fiber displacement sensor to a PZT stack, as shown in Fig. 2. One end of the PZT stack is bonded to a fixed platform and the other end to a light weight T-shaped base. Two points of the half-loop of the bend fiber are also glued to the platform and the base. The displacement produced by the PZT, when voltage is applied, changes the distance between the fixed points of the fiber and therefore changes the bend diameter. As it is shown in Fig. 1 above, a decrease in the bend diameter causes the peak of the spectral response to shift toward a lower wavelength. It is found that at some fixed operating wavelength and within some range of bend diameters corresponding to the range of voltages applied to the PZT the transmission loss of the bend fiber changes monotonically with the bend diameter. Thus, the transmission loss of the bend fiber will vary in proportion to the applied voltage.

Fig. 2 shows a schematic configuration of the voltage sensor in the ratiometric scheme. The voltage information is extracted using a ratiometric power measurement system. The measured ratio is independent on the input signal power variation that provides more stable and accurate measurements. The input signal is divided into two equal power signals, one of which goes to the reference arm and the other goes to the bend fiber. Two photodiodes and the associated electronics are used to measure the output power from the two arms. The unknown voltage can be found by measuring the power ratio of the two output photodiodes, assuming that the system is calibrated.

\section{Experimental results and discussion}

A commercial PZT stack AE0505D18 (manufactured by Tokin Corporation, Japan) was used as the transducer. It has a length of 


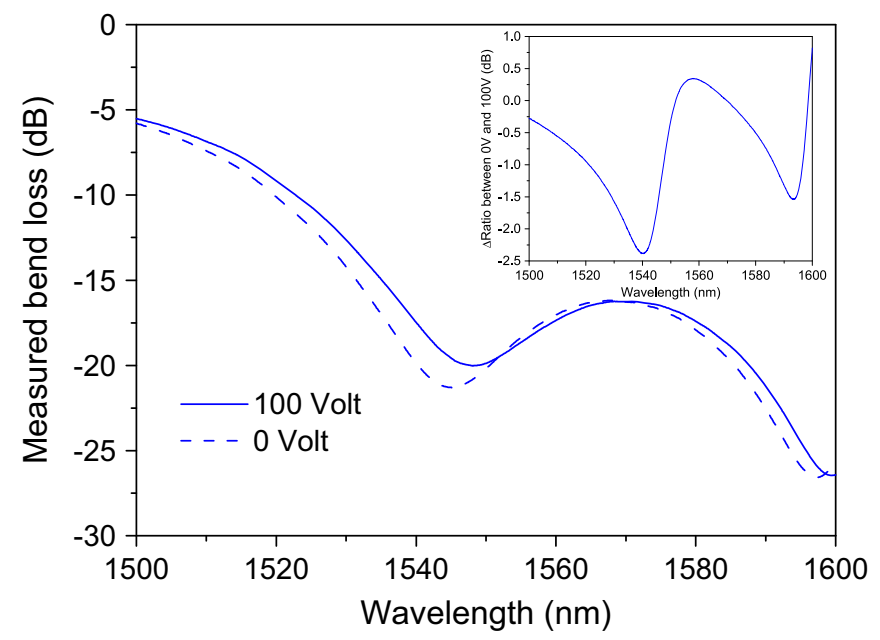

Fig. 3. Measured ratio spectral responses at 100 and $0 \mathrm{~V}$ (inset: ratio difference).

$20 \mathrm{~mm}$, cross section dimensions of $5 \times 5 \mathrm{~mm}$ and can produce the maximum elongation of $15 \mu \mathrm{m}$ at a DC voltage of $100 \mathrm{~V}$. The bare high bend loss fiber 1060XP was used for the voltage sensor head. The bend diameter of the fiber was in the range from 15 to $18 \mathrm{~mm}$ resulting in a single-peak spectral response over the wavelength range of 1500-1600 nm [13]. As shown in Fig. 2 the bare bend fiber is glued to the platform and the base, with a total length in between the fixed points of about $17 \mathrm{~mm}$.

A tunable laser TUNICS-PLUS was used as the input signal source. A single channel piezo controller MDT694A (Thorlabs) was used to supply the DC voltage from 0 to $100 \mathrm{~V}$ to the PZT stack. Initially two spectral responses of the output ratio were measured at voltages 0 and $100 \mathrm{~V}$ to select the appropriate operating wavelength. The measured spectral ratio responses at 0 and $100 \mathrm{~V}$ in the wavelength range of $1500-1600 \mathrm{~nm}$ with an increment of $0.1 \mathrm{~nm}$ are shown in Fig. 3. It can be seen that the spectral ratio response of a bare bent fiber is shifted to a lower wavelength when the voltage is applied. This spectral response shift to the lower wavelength region confirms the strain effect on the bare bent fiber as in Ref. [15].

For the purpose of power based measurement, it is necessary to select an optimal fixed operating wavelength for the ratiometric system. The difference in the measured ratio at 100 and $0 \mathrm{~V}$ versus wavelength is presented in the inset of Fig. 3. From the figure, one can see that a stronger voltage dependence is obtained at some wavelengths, which is more suitable as the operating wavelengths for the proposed voltage sensor. A wavelength of $1540 \mathrm{~nm}$ with a highest ratio difference of $-2.379 \mathrm{~dB}$ is selected as an operational wavelength in the following experimental investigation.

The measured ratio response versus voltage applied to the PZT from 0 to $100 \mathrm{~V}$ with an increment of $5 \mathrm{~V}$ at the wavelength of $1540 \mathrm{~nm}$, is presented in Fig. 4. A linear relation between the applied voltage and the ratio response is demonstrated with a slope of $0.0238 \mathrm{~dB} / \mathrm{V}$. To estimate the voltage measurement resolution of the system, step changes of $0.5 \mathrm{~V}$ from 20 to $22 \mathrm{~V}$ are applied to the fiber sensor with time intervals of $5 \mathrm{~s}$. The measured ratio variations versus time are shown in Fig. 5. It is clear that the resolution of the voltage sensing system is better than $0.5 \mathrm{~V}$. Thus it is demonstrated that the proposed fiber sensor with macrobending fiber structure, together with a PZT is suitable for DC voltage measurements in the range of voltages from 0 to $100 \mathrm{~V}$.

It is possible to extend the voltage range for the bent fiber sensor to higher voltages. The operating voltage depends on the PZT's strain-voltage characteristic. In Ref. [4], a PZT is used that can be operated over a much higher AC voltage range from 0 to $5 \mathrm{kV}$ with a maximum PZT displacement of about $19 \mu \mathrm{m}$, which is

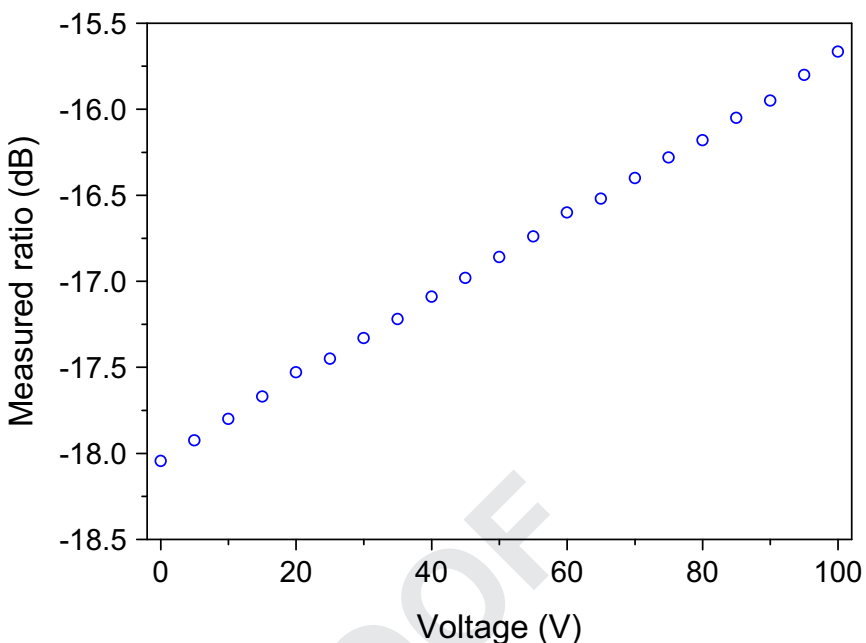

Fig. 4. Measured ratio response of the sensor against voltage $(Q \sim 100 \mathrm{~V})$ at the operating wavelength of $1540 \mathrm{~nm}$ (variation in ratio for a step change of $750 \mathrm{~nm}$ (corresponds to a $5 \mathrm{~V}$ voltage step applied to the PZT)).

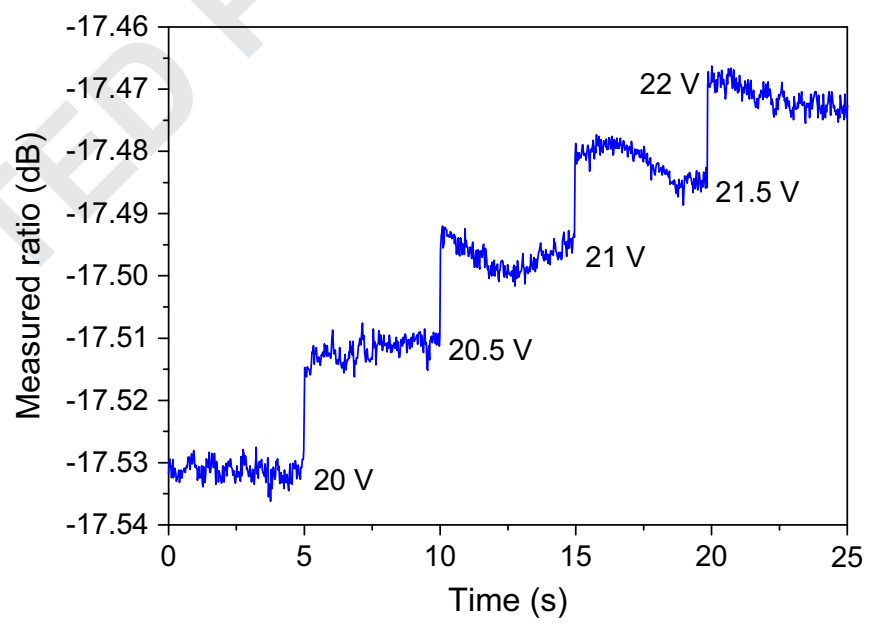

Fig. 5. Measured output ratio response of the sensor versus time $(0 \sim 25 \mathrm{~s})$ at the operating wavelength of $1540 \mathrm{~nm}$ (variation in ratio for a step voltage change of $0.5 \mathrm{~V})$.

similar to the maximum PZT displacement used in this paper. The maximum PZT displacement should be within the limits of the measureable displacement range of the bent fiber, which is approximately $250 \mu \mathrm{m}$ in the present case.

\section{Conclusions}

A macrobending fiber structure attached to a PZT transducer is proposed as a voltage sensor employed in a ratiometric power measurement scheme. A DC voltage sensor in the voltage range from 0 to $100 \mathrm{~V}$ with a resolution of about $0.5 \mathrm{~V}$ is demonstrated. The proposed fiber sensor has a low cost, fast measurement capability, and a potential for high voltage measurement applications.

\section{Acknowledgements}

Pengfei Wang is funded by the Irish Research Council for Science, Engineering and Technology, co-funded by the MarieCurie Actions under FP7. Qiang Wu is funded by Science Foundation Ireland under grant no. 07/SK/I1200. 


\section{References}

3 [1] Fusiek G, Niewczas P, Mcdonald JR. Feasibility study of the application of optical voltage and current sensors and an arrayed waveguide grating for aero-electrical systems. Sens Actuators A 2008;147:177-82.

5 [2] Martinez-Leom L, Diez A, Cruz JL, Andres MV. Frequency-output fiber-optic voltage sensor for high-voltage lines. IEEE, Rhoton Technol Lett 2001;13(9): 996-8.

[3] Kim S, Park J, Han W-T. Optical fiber AC voltage sensor. Microwave Opt Technol Lett 2009;51(7):1689-91.

9

[4] Niewczas P, Dziuda L, Fusiek G, Mcdonald JR. Design and evaluation of a preprototype hybrid fiber-optic voltage sensor for a remotely interrogated condition monitoring system. IEEE Trans Instrum Meas 2005;54(4):1560-4.

[5] Hatta AM, Semenova Y, Rajan G, Farrell G. A voltage sensor based on a singlemode-multimode-singlemode fiber structure. Microwave Opt Technol Lett 2010;52(8):1887-90.

[6] Wang P, Farrell G, Wang Q, Rajan G. An optimized macrobending-fiber-based edge filter. IEEE Photon Technol Lett 2007;19(15):1136-8.

[7] Wang P, Rajan G, Farrell G, Semenova Y. Temperature dependence of a macrobending edge filter based on a high bend loss fiber. Opt Lett 2008;33(21): $2470-2$.
[8] Wang P, Semenova Y, Wu Q, Farrell G, Ti Y, Zheng J. Macrobending singlemode fiber-based refractometer. Appl Opt 2009;48(31):6044-9.

[9] Grillet A, Kinet D, Witt J, Schukar M, Krebber K, Pirotte F, Depré A. Optical fiber sensors embedded into medical textiles for healthcare monitoring. IEEE Sens J 2008;8(7):1215-22.

[10] Hu R-P, Huang X-G. A simple fiber-optic flowmeter based on bending loss. IEEE Sens J 2009;9(12):1952-5.

[11] Sai VVR, Kundub T, Mukherji S. Novel U-bent fiber-optic probe for localized surface plasmon resonance based biosensor. Biosens Bioelectron 2009;24:2804-9.

[12] Wang P, Farrell G, Semenova Y, Rajan G. Influence of fiber manufacturing tolerances on the spectral response of a bend loss based all-fiber edge filter. Appl Opt 2008;47(16):2921-5.

[13] Wang P, Wang Q Farrell G, Rajan G, Freir T, Cassidy J. Investigation of macrobending losses of standard single mode fiber with small bend radii. Microwave Opt Technol Lett 2007;49(9):2133-8.

[14] Nam SH, Yin S. High-temperature sensing using Whispering Gallery mode resonance in bent optical fibers. IEEE Photon Technol Lett 2005;17(11): 2391-3.

[15] Wang P, Semenova Y, Wu Q Farrell G. Macrobending fiber based microdisplacement sensor utilizing Whispering-Gallery modes. Proc. SPIE 2009;7503: 750330. 